\title{
Conceptual Framework of Project Management for Space Industry Projects
}

\author{
Mohd Harridon ${ }^{1,2,3}$, Muhamad Nurazmi Abas ${ }^{1}$, Mohd Abdul Karim¹, Abdul Qaiyum Alidin ${ }^{1}$, Muhammad Asyraf \\ Mohd Niza ${ }^{1}$
}

\author{
${ }^{1}$ Space Technology Division Serba Dinamik Group Berhad \\ ${ }^{2}$ Malaysia Civil Defence Force \\ ${ }^{3}$ Universiti Kuala Lumpur Malaysian Institute of Aviation Technology
}

DOI: 10.29322/IJSRP.11.06.2021.p11405

http://dx.doi.org/10.29322/IJSRP.11.06.2021.p11405

\begin{abstract}
The Space Industry is a complex industry with various resources, processes, regulations, and other entities that merged and integrated to produce the end product. It's imperative to have a framework to manage all of the mentioned above in order to reduce wastage and gained the desired output within an optimum time frame. In this paper we had developed a conceptual framework pertaining to project management that could be utilized in space related projects.
\end{abstract}

Index Terms- Space Industry, Project Management, Framework, Space Projects

\section{INTRODUCTION}

$\mathrm{S}_{\mathrm{t}}$ pace Industry is a complex industry with numerous players taking stakes in the New Space Economy. It's imperative for stakeholders in the Space Industry to take an approach which is feasible, logical, and calculated in order to gain a Return of Investment (ROI) within an optimum time frame.

According to Yazici and Darici, the Space Industry consists of various entities such as global communication, management of aviation traffic, forecasting of weather, and others [1]. Yazici and Darici further stated that the New Space Economy would create enormous number of jobs and employments for the masses [1].

In order to control and manage the intricate entities in the Space Industry, it's vital to have an astute project management approach. The implementation of good project management would ensure resources are utilized in an optimum manner and wastage is kept low. Good project management also entails the Space Project would be completed within the required duration.

Hall stated that there are numerous project management approaches such as PERT, critical chain project management, CPM, and agile [2]. These approaches intended to clearly manage projects by sectioning the projects into manageable chunks and set appropriate milestones for each chunk [2].

Harridon had conducted research and survey and it was evidenced that projects with good management approach had led to successful completion of projects or missions within the desired time frame and capital [3]. Harridon had used data of Search and Rescue missions to gain insights upon the approaches of management that propel projects or missions into the correct path [3].

This publication is licensed under Creative Commons Attribution CC BY.

http://dx.doi.org/10.29322/IJSRP.11.06.2021.p11405
Numerous and myriad space projects are in existence or in the pipeline that contribute to the New Space Economy. Metzger indicated such projects are the way forward and GDP of countries dependable upon them in the near future [4]. According to Metzger, examples of such projects are space mining on the moon, nuclear fusion, terrestrial source of energy that is renewable, rocket propellant, and others [4]. While this not an exhaustive list, we can observe that these are projects of big potential and are able to provide mass employment.

\section{LITERATURE REVIEW}

Space Industry had shown enormous potential and with the advent of the New Space Economy, the Space Sector had seen great emergence of players and technologies. Barbaroux indicated that the government led era had began to diminish and most initiatives today were from the private and commercial sectors that compete to acquire the percentage of the space pie [5]. Barbaroux further mentioned that demands are currently high and that had created suppliers that were willing to meet those demands and Barbaroux stated that from 2008 till 2013 the number of payload launches into space had increased [5].

Weinzierl explained that in the year 2018, the total revenues pertaining to Space Industry were USD 300 billion and most of the revenues were generated by private entities or companies [6]. $\mathrm{He}$ also stated that the New Space Economy would be a self sustainable venture with a combination of small, middle, and large scale projects [6].

In the Space Industry, one of the most important aspects is the human resource or manpower. And the personnel in this particular industry should be able to withstand the strains and stresses that are inherently ingrained in the work. The personnel should be able to produce outputs that are desirable and to achieve this the workers should be continuously fit mentally and physically. Harridon mentioned that retaining fitness is desirable so that workers could produce their best results and avoid mistakes [7]. And this is vital as safety is uttermost important in the Space Industry.

Project Management is a science and an art simultaneously. It is a tool or method to coalesce entities together to achieve several milestones and goals. Al-Hajj indicated that the implementation of project management approach depends upon 
several factors and he surmised that some of those factors are the training received by the practitioners, human capital, and others [8]. Al-Hajj also said that project management approach should be adaptable to myriad situations since different situations require different approaches [8].

Harridon concurred with Al-Hajj and Harridon indicated that situations during Search and Rescue Missions require management of equipment and personnel which is adaptable to the mission whether it is sea, air, or land [9]. Harridon also reiterated the importance of viable management framework to propel the mission or project into successful realm [9].

Badewi had a perspective that the project should also be evaluated based upon the benefits that the project brings in [10]. He argued that a project should be capable of producing tangible and intangible benefits as this would make the project worthy of being implemented [10]. This makes sense as some quarters argued that projects should holistically benefit the society rather than degrading them.

Denis pointed out that the new contemporary trend in the New Space Economy is the existence of start ups and new entrepreneurs that are technology savvy and willing to press forward to upgrade the lifestyle of the masses through Space Technology [11]. These initiatives require a framework that is able to manage intricacies of the New Space Economy and this is where our framework comes into play.

\section{METHODOLOGY}

We had utilized the methodology in Figure 1 to build the project management conceptual framework for space related projects.

IDENTIFICATION

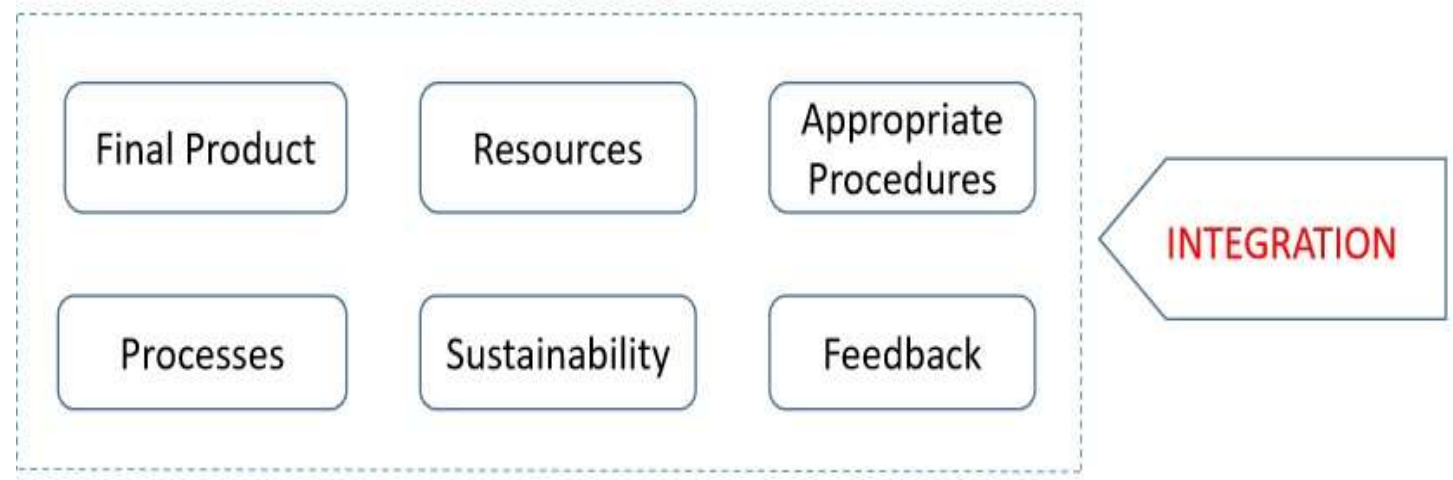

Figure 1. The Methodology that was Utilized

The development of the framework had involved identification of pertinent components for the production of the end product where the end product is myriad physical products such as rocket, launch pad, satellite, and others. End product also include myriad non physical products such as space capsule software, satellite software, launch software, and others. There were 6 pertinent components that were identified which were Final Product, Resources, Processes, Appropriate Procedures, Feedback, and Sustainability. All of these components were integrated to produce the project management conceptual framework. Below are the descriptions of each component.

Final Product - The Final Product is identified in comprehensive details in order to eradicate vague connotations. Vague connotations ensure the end product is not within the standard of the demand. Thus vague connotations should be avoided.

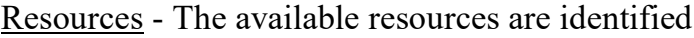

Processes - The necessary and appropriate processes to be actuated to gain the end product are identified

Appropriate Procedures - The procedures that are adequate and sufficient to develop the end product are identified

Feedback - The feedback that governs the reshaping of the end product is identified

Sustainability - The methods or ways that sustain the end product perpetually are identified

The Results Section of this paper lays out our conceptual framework.

\section{RESULTS}

The conceptual framework that we had produced is shown in Figure 2. 
(2)

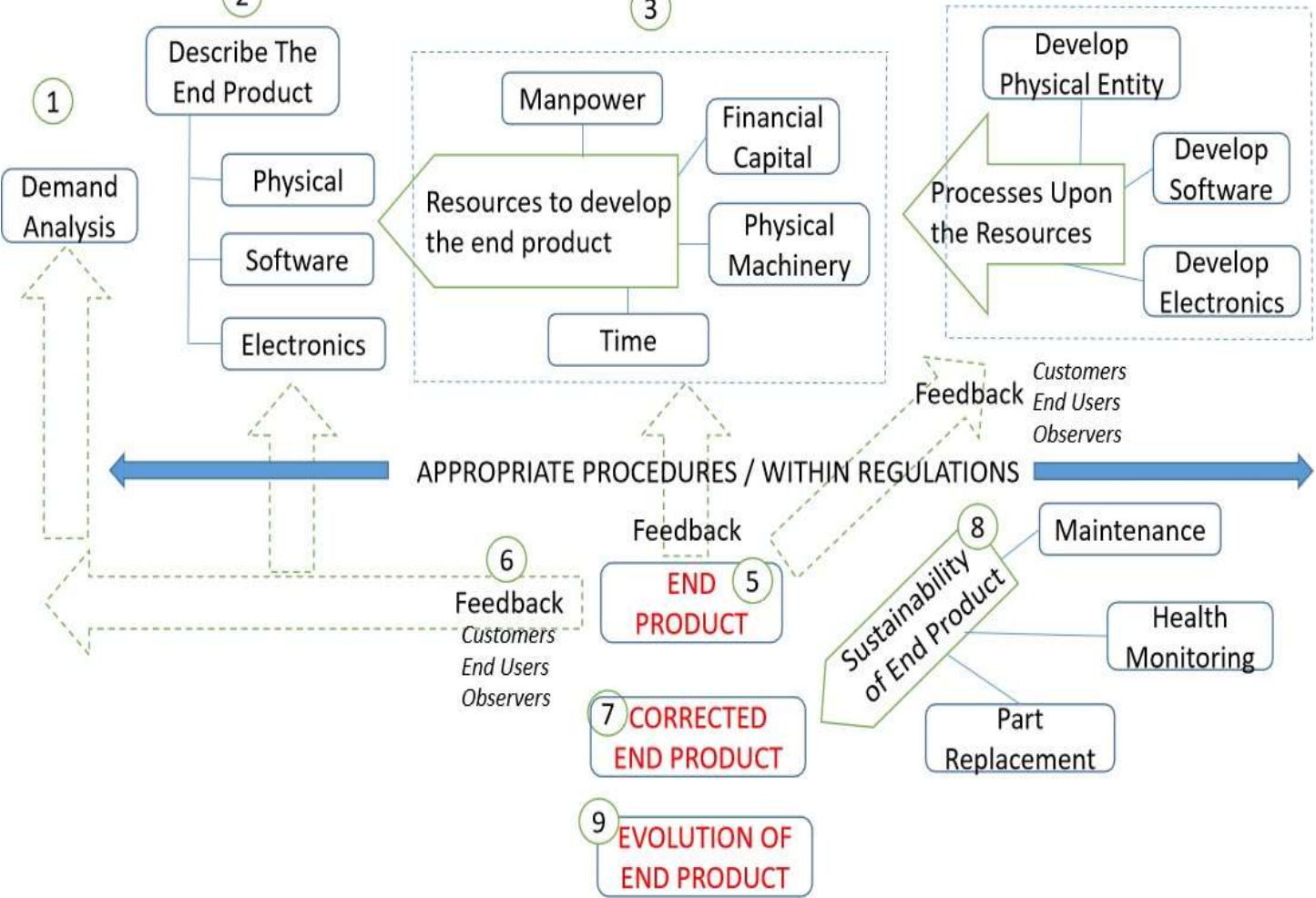

Figure 2. The Conceptual Framework of Project Management for Space Industry Projects

In Figure 2, we had used the methodology in Figure 1 to create a base or platform for our framework. This platform was then expended where several components and auxiliaries were added to produce a comprehensive framework shown in Figure 2. A more detail description of the framework is shown in the Discussion Section.

\section{DISCUSSION}

The Conceptual Framework that we had developed and shown in Figure 2 is read in sequence starting from number 1 till number 9 (the numbering are enclosed within circles). At number 1 , which is the start, it's imperative for us to analyze the demand from the public, private sectors, governments, stakeholders, and others in order to gauge their needs in the Space Industry. The analysis box can be further enhanced to indicate the type of analysis to be performed, whether is it Market Identification Analysis, Product Niche Analysis, Competition Analysis, or others.

The next step in our framework, which is labeled number 2, is to describe in comprehensive details the end product that we are going to produce. Again, the boxes under number 2 can be added to expand further the description of the end product. In describing the end product, the general idea is to initially describe the end product in terms of physical, software, and electronics and further enhance the description by adding sub boxes.

Let us take for example the end product to be a rocket that transports a satellite to geostationary orbit. The box physical describes the fuselage, fairing, engines, fuel, fins, and other physical means of the rocket. The box software describes the software that runs and control the rocket. And the box electronics describes the electrical and electronics that are etched upon the rocket.

Gaining a comprehensive description of the end product is uttermost important as it would eradicate vagueness and denote our end product in such a way that it fits and comply to various demands in an accurate manner.

The next step in our framework, which is labeled number 3, is to list down and utilize the available resources or to acquire the intended resources in order to fabricate the end product. The general resources normally used to produce the end product are manpower, financial capital, physical machinery, and time. Manpower denotes the human capital or workers at our disposal that can be utilized to fabricate the end product. Financial capital is the fund that is used to finance the project. Physical machinery refers to the equipment, tools, transport vehicles, machines, autoclaves, cranes, and other physical means that are used to fabricate the end product. Time denotes the duration available to complete or finish the project. This could also be denoted as the time frame agreed by all parties to complete the rolling out of the end product.

Number 4 in our framework denotes the processes used to utilize the resources and these processes are the activities that produce the end product. The processes are classified into 3 parts which are the processes that develop the physical entity of the end product, the processes that develop the software of the end product, and the processes that develop the electronics of the end product. For example, the autoclave process is one of the many processes that could be used to develop the physical entity of the end product. Meanwhile the computer programming process is used to develop the software of the end product. For the electronics of the end product, the wafer fabrication process is used to produce 
the electronics parts and other processes are available as well to fabricate the electronics section.

Peering at Number 5 in our framework, it shows our end product. But this is not the ending of the framework. At Number 6 of our framework, feedback is gained from the customers, end users, and observers. The customers are the ones that use the end product. An example would be the public that pays subscription to telecommunication company where the end product is the internet access. If the access is not smooth, the feedback from the public / customer is taken into account to improve the end product. The improvement is via correction of the end product and this is shown in Number 7 of our framework.

Number 8 in our framework is the sustainability of the end product. Taking again the internet access as example, to sustain the network continuously, the physical equipment needs to be maintained and the health or the performance of the equipment needs to be monitored. Also if parts of the equipment are degraded, they need to be replaced. All of these would ensure that the sustainability of the end product is attained and maintained.

Number 9 in our framework deals with the evolution of the end product. Take for example an aeroplane which had gone through numerous evolution for various purposes. The Boeing 737 started off as an airplane with analog instruments and the aircraft had evolved and currently almost all Boeing 737 utilized digital instruments.

Peering at our framework, it can be observed that the whole entities in the framework are governed by appropriate procedures and all tasks are to be within sufficient regulations. The Space Industry is highly regulated with several standards and manufacturing of physical space components are to follow rigid procedures. This is to ensure that safety is not compromised as it involves lives and financial losses.

For Space Industry Projects, the application of our framework would utilize entities related to the Space Industry. For example, taking a satellite as the end product, the resources needed (Number 3 in our framework) are electrical engineers, software engineers, 3D printer, funding from bank, adequate timeline to build the satellite, and others. Pertaining to Number 8 of our framework and in relation to the Space Industry Projects, let us take the Hubble Telescope as our real life example. In order to sustain the Hubble, maintenance was actuated where astronauts were transported to space to do repairs of the Hubble. The Hubble was also monitored to gauge it's performance and parts were also replaced. All of these conformed to our framework.

The gist of our framework is to give the users the leverage to practice good management. The framework in some sense guides the users to identify and map the components or entities related to their project in tandem with the structure of our framework. This leads to good management. According to Harridon, good management would lead to project or mission success and Harridon gave examples of Search and Rescue Missions that were successful due to good and and sensible approach towards management [12].

The framework that we had parlayed could be enhanced further by adding more sub boxes and giving in depth description. For example, for Number 3 in our framework, the manpower portion could be enhanced further by adding sub boxes. One of the sub boxes could be titled Physical Fitness as this is an important component of getting workers to be fit and therefore productive in their work. Harridon in his paper had outlined that those who are fit are more incline to produce their best works and Harridon had also spelled out methods to gain the desired fitness [13].

Too stated that in order to achieve the required deliverable, a structure is needed in order to guide the processes and resources toward the intended goals [14]. Too also went further by stating that there should be a monitoring system in placed in order to observe the progress of the project and this is inline with our framework where we had a feedback system in placed that acted as a monitoring system of our end product.

\section{CONCLUSIONS}

The framework that we had produced was an attempt to quantify the entities that are involved directly or indirectly in relation to the Space Industry. The Space Industry is a complex industry with many interweaving components. Our framework of Project Management detailed out the relevant Space Industry entities and related them with each other and thus given them a symbiosis relationship. This allow users to manage the space related projects in an effective manner and our framework can be used or utilized as a guideline. Our framework is also sequential in nature where space entities are ordered or arranged sequentially and users are encouraged to follow the sequence to gain appropriate results.

\section{REFERENCES}

[1] Yazici, A. M., and Darici, S. (2019). The New Opportunities in Space Economy. Journal of the Human and Social Science Researches, 8 (4), 32523271

[2] Hall, N., "Project Management : Recent Developments and Research Opportunities", Journal of Systems Science and Systems Engineering, Volume 21, Pages 129-143, 2012, DOI : 10.1007/s11518-012-5190-5

[3] Harridon, M., "Factors that Affect the Success of Search and Rescue Missions : Perceptions of Search and Rescue Crews of Malaysian Police Air Wing", International Journal of Scientific and Research Publications, Volume 10, Issue 11, November 2020, ISSN 2250-3153, DOI : 10.29322/IJSRP.10.11.2020.p10727

[4] Metzger, P., "Space Development and Space Science Together, an Historic Opportunity", Space Policy (2016), DOI : 10.1016/j.spacepol.2016.08.004

[5] Barbaroux, P., "The Metamorphosis of the World Space Economy : Investigating Global Trends and National Differences among Major Space Nation's Market Structure", Journal of Innovation Economics \& Management, Volume 2, Issue 20, 2016, Pages 9-35, ISBN 9782807390041.

[6] Weinzierl, M., "Space, the Final Economic Frontier", Journal of Economic Perspectives, Volume 32, Number 2, Spring 2018, Pages 173-192, DOI : 10.1257/jep.32.2.173

[7] Harridon, M., "Health Assessment of Academicians through Body Mass Index Evaluation and Relationship with Strain", International Journal of Scientific and Research Publications, Volume 10, Issue 11, November 2020 , ISSN 2250-3153, DOI : 10.29322/IJSRP.10.11.2020.p10781

[8] Al-Hajj, A., "The Impact of Project Management Implementation on the Successful Completion of Projects in Construction", International Journal of Innovation, Management and Technology, Volume 9, Number 1, February 2018, DOI : 10.18178/ijimt.2018.9.1.781

[9] Harridon, M., "Perception of Search and Rescue Crew of Malaysian Police Air Wing towards General Issues of Search and Rescue", International Journal of Scientific and Research Publications, Volume 10, Issue 10, October 2020, ISSN 2250-3153, DOI : 10.29322/IJSRP.10.10.2020.p10630

[10] Badewi, A., "The Impact of Project Management (PM) and Benefits Management (BM) Practices on Project Success : Towards Developing a Project Benefits Governance Framework", International Journal of Project 
Management, May 2015, JPMA - 01779, DOI : 10.1016/j.ijproman.2015.05.005

[11] Denis, G., "From New Space to Big Space : How Commercial Space Dream is Becoming a Reality", Acta Astronautica, Volume 166, January 2020, Pages 431-443, DOI : 10.1016/j.actaastro.2019.08.031

[12] Harridon, M., "Incident Analyses of Helicopter Guimbal Cabri G2", International Journal of Scientific and Research Publications, Volume 10, Issue 12, December 2020, ISSN 2250-3153, DOI : 10.29322/IJSRP.10.12.2020.p10809

[13] Harridon, M., "Rate of Perceived Exertion of Potential Avionics Male Students and Proposed Exercises to Decrease Strain", International Journal of Engineering \& Technology, 7 (4.36) (2018) 374-378, DOI : 10.14419/ijet.v7i4.36.28145

[14] Too, E., "The Management of Project Management : A Conceptual Framework for Project Governance", International Journal of Project Management, Volume 32, Issue 8, November 2014, Pages 1382-1394, DOI : 10.1016/j.ijproman.2013.07.006

\section{AUTHORS}

First Author - Mohd Harridon, Space Technology Division Serba Dinamik Group Berhad, Malaysia Civil Defence Force, Universiti Kuala Lumpur Malaysian Institute of Aviation

Technology, mdharridon@unikl.edu.my

Second Author - Muhamad Nurazmi Abas, Space Technology

Division Serba Dinamik Group Berhad

Third Author - Mohd Abdul Karim, Space Technology

Division Serba Dinamik Group Berhad

Fourth Author - Abdul Qaiyum Alidin, Space Technology Division Serba Dinamik Group Berhad

Fifth Author - Muhammad Asyraf Mohd Niza, Space

Technology Division Serba Dinamik Group Berhad 